REVISTA DE GEOCIÊNCIAS DO NORDESTE

Northeast Geosciences Journal

v. $7, \mathrm{n}^{\mathrm{o}} 2(2021)$

ISSN: $2447-3359$

https://doi.org/10.21680/2447-3359.2021v7n2ID22034

\title{
ANÁLISE DE ÍNDICES DE VULNERABILIDADE FÍSICA COM USO DE GEOTECNOLOGIAS NA REGIÃO DA BARREIRA DO INFERNO/RN
}

\author{
Venerando Eustáquio Amaro ${ }^{1}$; Ada Cristina \\ Scudelari $^{2}$; Diego Souza de Oliveira ${ }^{3}$; Ivens \\ Lorran Clemente de Lacerda ${ }^{4}$; Maria de Fátima \\ Alves de Matos ${ }^{5}$
}

${ }^{1}$ Geólogo, Departamento de Engenharia Civil, Universidade Federal do Rio Grande do Norte (UFRN), Natal/RN, Brasil.

ORCID: https://orcid.org/0000-0001-7357-2200

Email: venerando.amaro@gmail.com

${ }^{2}$ Eng. Civil, Departamento de Engenharia Civil, Universidade Federal do Rio Grande do Norte (UFRN), Natal/RN, Brasil.

ORCID: https://orcid.org/0000-0001-7594-1196

Email: adaufrn@gmail.com

${ }^{3}$ Eng. Civil, Departamento de Engenharia Civil, Faculdade Maurício de Uninassau (UNINASSAU). Natal/RN, Brasil.

ORCID: https://orcid.org/0000-0002-2700-2917

Email: diego_s.oliveira@ hotmail.com

${ }^{4}$ Eng. Civil, Programa de Pós-Graduação em Engenharia Civil, Universidade Federal do Rio Grande do Norte (UFRN), Natal/RN, Brasil.

ORCID: https://orcid.org/0000-0002-1331-2527

Email: ivenslorran@hotmail.com

${ }^{5}$ Geógrafa, Programa de Pós-Graduação em Engenharia Civil, Universidade Federal do Rio Grande do Norte (UFRN), Natal/RN, Brasil.

ORCID: https://orcid.org/0000-0002-2864-2027

Email: mfatimaalves.m@gmail.com

\section{Resumo}

Este estudo apresenta a determinação de índices de vulnerabilidade física na região da Barreira do Inferno, Município de Parnamirim/RN. Os índices de Vulnerabilidade Natural (VN) e Vulnerabilidade Ambiental (VA) foram calculados por meio da análise estatística ponderada das classes temáticas de geomorfologia, declividade, solos, vegetação, geologia, uso e ocupação do solo. As variáveis temáticas foram avaliadas para redução da subjetividade e da dimensionalidade por meio do Processo Analítico Hierárquico e da Análise por Principais Componentes. Os resultados mostraram o domínio de classes de média, alta e muita alta vulnerabilidade em $75 \%$ e $79,1 \%$ da área total nos mapas de VN e VA, respectivamente. O Índice de Vulnerabilidade Costeira (IVC) à erosão foi estabelecido a partir de variáveis físicas e dinâmicas para três diferentes cenários futuros de mudanças climáticas do Painel Intergovernamental sobre Mudanças do Clima. O IVC em 100\% da linha de costa (LC) é de baixa vulnerabilidade no cenário otimista. Na projeção pessimista $31 \%$ da extensão da LC está em vulnerabilidade média.

Palavras-chave: Vulnerabilidade Natural; Vulnerabilidade Ambiental; IVC; Nordeste do Brasil.

\section{PHYSICAL VULNERABILITY INDICES ANALYSIS USING GEOTECHNOLOGIES ON THE REGION OF BARREIRA DO INFERNO/RN}

\begin{abstract}
This study presents the determination of physical vulnerability indexes on the region of Barreira do Inferno, Municipality of Parnamirim/RN. The natural vulnerability (NV) and environmental vulnerability (AV) indexes were calculated through weighted statistical analysis of the thematic classes of geomorphology, slope, soils, vegetation, geology, land use and occupation. The thematic variables were evaluated to reduce subjectivity and dimensionality through the Hierarchical Analytical Process and Principal Component Analysis. The results showed the domain of intermediate, high and very high vulnerability classes in $75 \%$ and $79.1 \%$ of the total area in the VN and VA maps, respectively. The Coastal Vulnerability Index (CVI) to erosion was established based on physical and dynamic variables for three different future climate change scenarios of the Intergovernmental Panel on Climate Change. The IVC in $100 \%$ of the coastline is of low vulnerability in the optimistic scenario. In the pessimistic projection $31 \%$ of the shoreline extension is of intermediate vulnerability.
\end{abstract}

Keywords: Natural Vulnerability; Environmental Vulnerability; CVI; Northeast Brazil. 


\section{ANÁLISIS DE ÍNDICES DE VULNERABILIDAD FÍSICA UTILIZANDO GEOTECNOLOGÍAS EN LA REGIÓN DE BARREIRA DO INFERNO/RN}

\section{Resumen}

Este estudio presenta la determinación de los índices de vulnerabilidad física en la région de la Barreira do Inferno, Municipio de Parnamirim/RN. Los índices de vulnerabilidad natural (VN) y vulnerabilidad ambiental (VA) se calcularon mediante análisis estadísticos ponderados de las clases temáticas de geomorfología, pendiente, suelos, vegetación, geología, uso del suelo y ocupación. Las variables temáticas se evaluaron para reducir la subjetividad y dimensionalidad a través del Proceso Analítico Jerárquico y el Análisis de Componentes Principales. Los resultados mostraron el dominio de las clases de vulnerabilidad media, alta y muy alta en el $75 \%$ y el $79,1 \%$ del área total en los mapas VN y VA, respectivamente. El índice de vulnerabilidad costera (IVC) a la erosión se estableció sobre la base de variables físicas y dinámicas para tres escenarios de cambio climático futuros diferentes del Grupo Intergubernamental de Investigación sobre el Cambio Climático. El CIV en el $100 \%$ de la costa es de baja vulnerabilidad en el escenario optimista. En la proyección pesimista, el $31 \%$ de la extensión de la costa está en vulnerabilidad media.

Palabras-clave: Vulnerabilidad natural; Vulnerabilidad Ambiental; IVC; Noreste de Brasil.

\section{INTRODUÇÃO}

As modificações físicas nas orlas marítimas têm se intensificado em decorrência do incremento na frequência e intensidade de eventos climáticos extremos e ao aumento na densidade demográfica e nas instalações de infraestruturas, geralmente de modo desordenado (BORUFF et al., 2005). Segundo a Organização das Nações Unidas (UNDESA, 2017), pelo menos 600 milhões de pessoas, ou quase $10 \%$ da população mundial em 2017, vivem em zonas costeiras que estão a menos de $10 \mathrm{~m}$ acima do nível do mar e cerca de 2,4 bilhões de pessoas, ou $40 \%$ da população mundial, habitam até $100 \mathrm{~km}$ de distância da linha de costa (LC).

As comunidades costeiras, sobretudo aquelas estabelecidas em domínios morfológicos planos, baixos e próximos à linha de água, estão sujeitas aos riscos e perigos induzidos pelas alterações climáticas, tais como: o aumento do nível relativo do mar (NRM), o aumento na frequência e intensidade de tempestades, o incremento na energia das forçantes hidrodinâmicas (MCGRANAHAN et al., 2007). Tais episódios, cada vez mais frequentes, aumentam a exposição potencial das populações, por exemplo, aos processos de erosão e inundações costeiras, procedentes da combinação sinérgica entre fatores como ventos fortes, clima de ondas altas, marés altas e eventos extremos de precipitação. Igualmente, tais condições representam ameaça significativa aos ecossistemas costeiros, ao potencializar a intrusão salina em águas superficiais e subterrâneas e ao reduzir ecossistemas nas zonas úmidas costeiras, como manguezais e restingas (NICHOLLS et al., 2007). Portanto, o entendimento dessas inter-relações é fundamental para o planejamento e a gestão costeira, como subsídio à avaliação tanto dos benefícios advindos de decisões antecipadas e seguras sobre adaptações às influências climáticas, quanto dos custos resultantes na demora ou falta de ações mitigadoras no presente (KULP et al., 2019).

Por se tratar de unidade geográfica especialmente sujeita à complexidade de interações entre as variáveis físicas e os fatores socioeconômicos, a orla marítima possui características específicas ao longo de sua extensão e, assim, manifesta vulnerabilidades distintas para cada trecho (BUSMAN et al., 2016; BRAGA; PIMENTEL, 2019). O termo vulnerabilidade pode ser descrito como o conjunto de características de uma comunidade, derivado de variáveis físicas, socioeconômicas e ambientais, que determinam sua capacidade em antecipar, sobreviver, resistir e se recuperar do impacto de eventos naturais perigosos (KOLLURA, 1996).

Os estudos mais abrangentes sobre vulnerabilidade costeira à erosão e inundação integram, notadamente por meio de índices, os componentes do meio físico e socioeconômico, em escalas de abordagem regional a local, no intuito de compreender as relações entre a suscetibilidade física dos trechos costeiros e as comunidades costeiras (GORNITZ, 1990; MCLAUGHLIN et al. 2002; BORUFF et al., 2005). Outra abordagem é a avaliação das variáveis do meio físico natural, ou a vulnerabilidade natural (VN), e a vulnerabilidade ambiental (VA, TAGLIANI, 2003; GRIGIO et al., 2004), onde a VN expõe as fragilidades do ambiente ponderando, designadamente, fatores físicos como: geologia, geomorfologia, declividade, pedologia e cobertura vegetacional. Já a VA avalia o grau de suscetibilidade do ambiente a um impacto potencial instigado por determinado uso antrópico. Igualmente, o termo vulnerabilidade do meio físico natural, ou vulnerabilidade física (BUSMAN et al., 2016), distingue a maior ou menor estabilidade das variáveis físicas dos ecossistemas, segundo o princípio da ecodinâmica de Tricart (1977). Conforme este conceito, as variáveis físicas são consideradas mais estáveis, logo menos vulneráveis, quanto mais preponderarem processos pedogenéticos e menos estáveis, assim mais vulneráveis, quando dominarem processos morfogenéticos.

Para conjeturar as vulnerabilidades físicas das orlas marítimas diante das mudanças climáticas, uma versão ponderada foi designada Índice de Vulnerabilidade Costeira (IVC), utilizando dados de geomorfologia costeira, declividade, alteração do NRM, altura significativa média de ondas, amplitude média das marés e a taxa histórica de mudanças na LC (GORNITZ, 1991; GORNITZ et al., 1994). Esta proposta de IVC foi, posteriormente, adaptada aos diferentes contextos regionais e locais de litorais pelo mundo (THIELER; HAMMAR-KLOSE, 2000; BORUFF et al., 2005; OZYURT, ERGIN, 2010; MARTINS, 2015; BUSMAN et al., 2016; PANTUSA et al., 2018; GERRITY et al., 2018).

Assim, a vulnerabilidade à erosão é um conceito espacial de identificação de trechos litorâneos e atividades socioeconômicas suscetíveis aos distúrbios resultantes da erosão costeira (BEVACQUA et al., 2018). Neste contexto, os mapas de índices de vulnerabilidade costeira à erosão contribuem para o planejamento do uso e cobertura do solo de modo sustentável, no entendimento dos impactos da dinâmica costeira e da resiliência da orla marítima, nas diferentes escalas de execução (regional a local), agregando insumos aproveitáveis na formulação de políticas públicas de gestão costeira integrada (ZHU et al., 2019). $\mathrm{Na}$ escala local, tais estudos são particularmente relevantes na 
avaliação de fatores que afetarão o estado atual da orla marítima diante de eventuais desastres, subsidiando o gerenciamento para redução de riscos costeiros frente aos eventos extremos climáticos e aumento do NRM (PARTHASARATHY et al., 2015).

Este artigo tem como objetivo definir e avaliar índices de vulnerabilidade física na orla marítima da Barreira do Inferno, Município de Parnamirim/RN, que consiste em uma área de preservação ambiental permanente, cujo entorno vem sofrendo intensa pressão imobiliária.

\section{CARACTERIZAÇÃO DA ÁREA DE ESTUDO}

A área de estudo possui $24 \mathrm{~km}^{2}$ majoritariamente nos domínios do Centro de Lançamentos da Barreira do Inferno (CLBI) e parte de seu entorno, com cerca de $11 \mathrm{~km}$ de extensão de LC, localizado na orla marítima do Município de Parnamirim/RN, região metropolitana sul da cidade de Natal/RN (Figura 1).

Esta orla marítima oriental do RN apresenta clima tropical de verão seco, tipo As de Köppen, com regime de precipitação de ampla oscilação temporal, estação chuvosa concentrada entre abril e julho, precipitação anual média de $1.620 \mathrm{~mm}$ e temperatura anual média de $26,3^{\circ} \mathrm{C}$ (ALVARES et al., 2013; CARVALHO et al., 2020). Os ventos alísios de sudeste são dominantes, com estimativa de $95 \%$ de ocorrência com intensidades inferiores a 5,2 $\mathrm{m} / \mathrm{s}$ e $90 \%$ de com velocidade menor ou igual a $5,0 \mathrm{~m} / \mathrm{s}$, mais fortes entre os meses de agosto e setembro, sendo os mais fracos em abril (BARROS et al., 2013). O regime é de mesomarés semidiurnas com amplitudes médias de $2,2 \mathrm{~m}$ para as marés de sizígia e de 1,1 m para as marés de quadratura (Carta náutica DHN/MB, n. ${ }^{\circ} 810$ ). No clima de ondas há predominância, em todas as estações do ano, de ondas de leste-sudeste e, sobretudo no verão, de leste, com alturas de onda significativa variando entre 0,5m e 2,8m (ALMEIDA et al., 2015). As correntes de deriva litorânea geram transporte de sedimentos de sul para norte (MATOS et al., 2020).

O contexto geológico corresponde à Plataforma de Natal e sua plataforma continental contígua, arranjada entre o Alto de Mamanguape a sul e o Alto de Touros a norte, que possui correlações estratigráficas com a Bacia Potiguar e contato com a Bacia Paraíba-Pernambuco na falha de Mamanguape (BARBOSA et al., 2007). A Plataforma de Natal é estruturada em grábens e horsts de direções gerais NE $\left(40^{\circ}-60^{\circ} \mathrm{Az}\right)$ e NW $\left(300^{\circ}-\right.$ $320^{\circ} \mathrm{Az}$ ), que condicionam as unidades geológicas do embasamento cristalino, as unidades litológicas do Cretáceo, até os litofácies da Formação Barreiras do Mioceno-Plioceno (BEZERRA et al., 2001). As falésias marinhas ativas presentes no limite leste do CLBI expõem afloramentos de litofácies sedimentares da Formação Barreiras, onde dominam intercalações e interdigitações de conglomerados, arenitos e lamitos que denotam sistemas deposicionais continentais de leques aluviais e fluviais entrelaçados e meandrantes (ARAÚJO et al., 2006). Este alinhamento de falésias marinhas ativas conforma a borda de Tabuleiro Costeiro na área de estudo, com desnível de até $20 \mathrm{~m}$, de topo plano capeado por unidades do Quaternário, que incluem terraços aluvionares, como nas margens do Rio Pium que traça o limite sudoeste e sul da área de estudo, e sedimentos eólicos nos campos de dunas móveis e fixadas por vegetação.
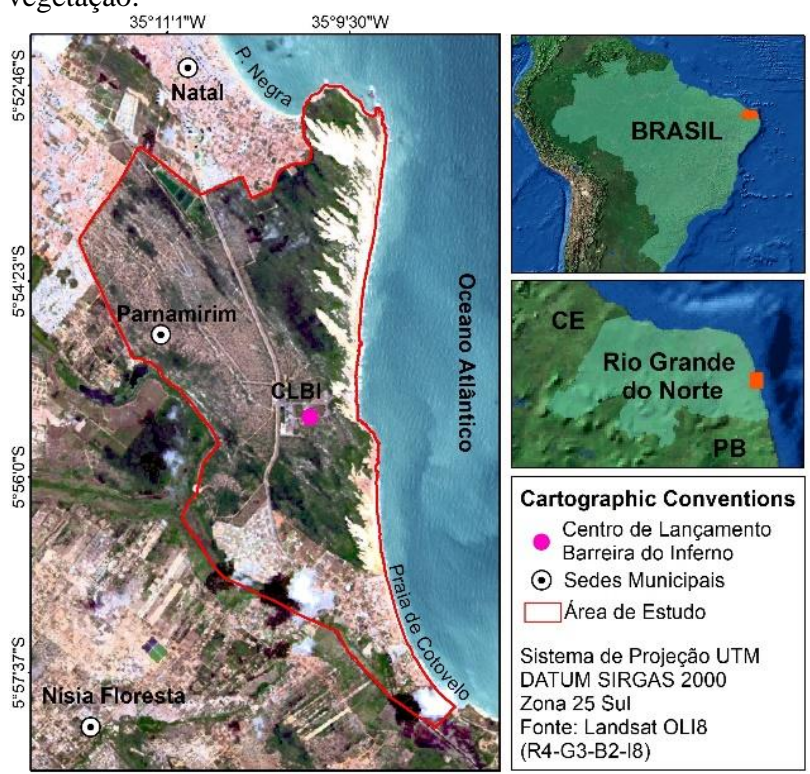

Figura 1 - Mapa de localização da área de estudo nos limites do Centro de Lançamentos da Barreira do Inferno (CLBI) e parte de seu entorno, Município de Parnamirim, litoral oriental do Rio Grande do Norte.

Quanto aos tipos de solos dominam os Neossolos Quartzarênicos de origem relacionada às areias marinhas eutróficas de pós-praia e campos de dunas, os Argissolos Vermelho-Amarelos e Neossolos oriundos do intemperismo das litofácies sedimentares da Formação Barreiras (SANTOS et al., 2018; CPRM, 2010).

A vegetação dominante é classificada como Floresta Estacional Semidecidual e Floresta de Restinga, ambas pertencentes ao domínio da Mata Atlântica (VELOSO et al., 1991), com elementos de Caatinga e Tabuleiro Costeiro (FRACASSO, 2005).

O recorte geográfico do CLBI é considerado área de preservação permanente (APP), restrita ao uso como base militar, com preponderância de campos de dunas móveis e fixas, de cobertura vegetacional conservada dentro de seus limites. Contudo, porções do seu entorno tem sofrido crescente pressão ocupacional, sobretudo na porção sul fronteira com a praia de Cotovelo e na porção norte limítrofe com a praia de Ponta Negra, ambas de intensa especulação imobiliária. 


\section{METODOLOGIA}

$\mathrm{Na}$ análise dos índices de VN, VA e IVC adaptou-se alguns dos procedimentos metodológicos propostos por Grigio et al. (2004), Busman (2016) e Busman et al. (2016), com base na análise espacial e estatística de mapas temáticos do meio físico, uso e cobertura do solo. Tais mapas temáticos foram readequados em escala de 1:50.000 após a interpretação de imagens multiespectrais e multitemporais da série LANDSAT, submetidas ao Processamento Digital de Imagens (PDI) em ambiente de Sistema de Informações Geográficas (SIG).

\subsection{Elaboração dos Mapas Temáticos}

A elaboração dos mapas temáticos (Figura 2) contou, com o levantamento cartográfico prévios nas escalas 1:100.000 e 1:250.000, selecionados em repositórios de dados digitais de instituições públicas: geologia, em escala 1:100.000 (Serviço Geológico Brasileiro/Companhia de Pesquisa de Recursos Minerais - SGB/CPRM), geomorfologia, vegetação e solos, ambos em escala 1:250.000 (Instituto Brasileiro de Geografia e Estatística - IBGE e Empresa Brasileira de Pesquisa Agropecuária - EMBRAPA), declividade, em escala 1:25.000 (Secretaria do Estado do Turismo do RN - SETUR e Secretaria de Estado da Infraestrutura-SIN), como detalhado na Tabela 1. Com a verificação em campo de todos as variáveis naturais e antrópicas, todos os mapas foram readequados à escala 1:50.000 e recondicionados à mesma base cartográfica, com o datum SIRGAS 2000 e o Sistema de Coordenadas Universal Transversa de Mercator (UTM) Zona 25-Sul, em ambiente SIG. A escala 1:50.000 é condizente com orientações do Ministério do Meio Ambiente para elaboração de instrumentos norteadores do planejamento em locais de alto risco e sensibilidade ambiental, para correlação ao contexto regional mais amplo (p.ex. MMA, 2004).

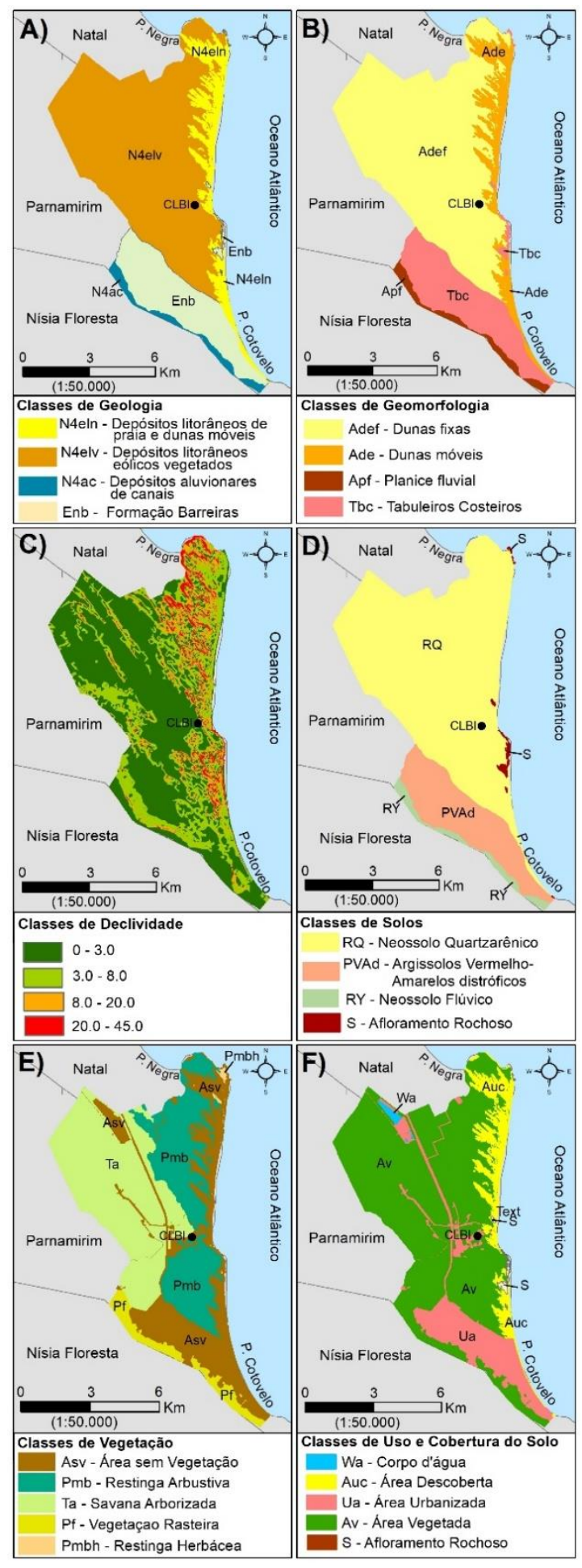

Figura 2 - Mapas temáticos da área de estudo no CLBI: (A) Geologia; (B) Geomorfologia; (C) Declividade; (D) Pedologia; (E) Vegetação; $(F)$ Uso e cobertura do solo. 
Tabela 1 - Fontes das bases de dados digitais de repositórios públicos para a elaboração dos mapas temáticos atualizados da área de estudo.

\begin{tabular}{|c|c|}
\hline \multicolumn{2}{|r|}{ Mapas Temáticos } \\
\hline $\begin{array}{l}\text { Mapa de } \\
\text { Declividade }\end{array}$ & $\begin{array}{l}\text { Fonte: Dados vetoriais do projeto Polo } \\
\text { Costa Dunas, com restituição } \\
\text { aerofotogramétrica, da Secretaria do } \\
\text { Estado do Turismo do RN (SETUR) e } \\
\text { Secretaria de Estado da Infraestrutura } \\
\text { (SIN), reprocessados em ambiente SIG. }\end{array}$ \\
\hline $\begin{array}{l}\text { Mapa de } \\
\text { Geologia }\end{array}$ & $\begin{array}{l}\text { Fonte: Dados vetoriais do Serviço } \\
\text { Geológico do Brasil-Companhia de } \\
\text { Pesquisa de Recursos Minerais (SGB- } \\
\text { CPRM), Folha Natal SB.25-V-C-C, } \\
\text { reprocessados em ambiente SIG. }\end{array}$ \\
\hline $\begin{array}{l}\text { Mapa de } \\
\text { Geomorfologia }\end{array}$ & $\begin{array}{l}\text { Fonte: Dados vetoriais do Instituto } \\
\text { Brasileiro de Geografia e Estatística } \\
\text { (IBGE), Folha SB-25, reprocessados em } \\
\text { ambiente SIG. }\end{array}$ \\
\hline Mapa de Solos & $\begin{array}{l}\text { Fonte: Dados vetoriais do Instituto } \\
\text { Brasileiro de Geografia e Estatística } \\
\text { (IBGE), Folha SB-25, reprocessados em } \\
\text { ambiente SIG. }\end{array}$ \\
\hline $\begin{array}{l}\text { Mapa de } \\
\text { Vegetação }\end{array}$ & $\begin{array}{l}\text { Fonte: Dados vetoriais do Instituto } \\
\text { Brasileiro de Geografia e Estatística } \\
\text { (IBGE), Folha SB-25, reprocessados em } \\
\text { ambiente SIG. }\end{array}$ \\
\hline $\begin{array}{l}\text { Mapa de Uso e } \\
\text { Cobertura do } \\
\text { Solo }\end{array}$ & $\begin{array}{l}\text { Fonte: Imagem digital submetida a } \\
\text { Classificação Supervisionada }\end{array}$ \\
\hline
\end{tabular}

\subsection{Detecção das Linhas de Costa - LC}

No levantamento cartográfico prévio foram selecionas as imagens multiespectrais dos satélites LANDSAT 5-TM e LANDSAT 8-OLI dos anos de 1984, 1993, 2005 e 2015 nos catálogos online do Instituto Nacional de Pesquisas Espaciais (INPE) e da United States Geological Survey (USGS) para diagnóstico da evolução dinâmica da extensão da LC, taxas de erosão e acreção, com base nos módulos estatísticos do Digital Shoreline Analysis System (DSAS, USGS). No intuito de amenizar as incertezas no cálculo das taxas de erosão e acreção, como resultado representativo da dinâmica sedimentar de longo prazo (1984 a 2015), as imagens analisadas apresentaram condições similares de preamar no instante do imageamento, entre $1,22 \mathrm{~m}$ e $1,76 \mathrm{~m}$.

As imagens foram submetidas aos procedimentos de calibração radiométrica, correção atmosférica e técnica de realce de bordas pelo índice de diferença normalizada da água (NDWI, sigla em inglês para Normalized Difference Water Index; GAO, 1996), aumentando a precisão na vetorização. O Modelo Digital de Elevação (MDE) foi obtido dos dados altimétricos da Missão Topográfica Radar Shuttle (SRTM, sigla em inglês para Shuttle Radar Topography Mission) com resolução espacial de 30m, do catálogo online do USGS. As imagens multiespectrais utilizadas foram das faixas do visível-infravermelho (bandas 1 a 5 e 7 do LANDSAT 5-TM, e bandas 1 a 7 do LANDSAT 8-OLI) com resolução espacial de 30m, e a pancromática (banda 8) do LANDSAT 8-OLI com resolução espacial de $15 \mathrm{~m}$.

O georreferenciamento das imagens foi efetuado na projeção cartográfica Universal Transversa de Mercator (UTM) Zona 25Sul, datum SIRGAS 2000, elipsoide do Sistema Geodésico de Referência de 1980, corrigidas as distorções e degradações nas imagens do LANDSAT 5-TM de 1984, 1993 e 2005 com erro médio quadrático inferior a 0,5 e conferindo as correções geométricas já apresentadas nas imagens do LANDSAT 8-OLI de 2015. Por fim, foi realizada a análise estatística das bandas multiespectrais para situarem correlações e favorecerem a escolha de aplicações de técnicas de PDI.

A Tabela 2 apresenta os tratamentos em PDI para realces das feições temáticas, como as composições coloridas no sistema de cores RGB (Red-Green-Blue) usando bandas isoladas e razões de bandas. A imagem pancromática (banda 8) do LANDSAT 8-OLI foi integrada à camada Intensity (I) do sistema de cores híbrido RGBI (Red-Green-Blue-Intensity), apurando a resolução espacial para $15 \mathrm{~m}$ e destacando as propriedades texturais das feições em superfície. O conjunto de imagens multiespectrais foi avaliado quanto à redundância espectral em análise multivariada por Análise por Principais Componentes (PC) e selecionadas aquelas PC de menor correlação, para uso como bandas isoladas nos sistemas RGB e RGBI. Todos os tripletes selecionados como de melhor qualidade visual foram tiveram ainda ajustes histogrâmicos de contrastes.

Os melhores tripletes de bandas multiespectrais do LANDSAT 8-OLI do ano de 2015 foram interpretados e vetorizados em ambiente SIG para confecção dos mapas de: geologia (Figura 2A); geomorfologia (Figura 2B); declividade, derivado do MDE (Figura 2C); solos (Figura 2D), vegetação (Figura 2E) e uso e cobertura do solo (Figura 2F). Tais mapas temáticos foram readequados de mapas pré-existentes, em diferentes escalas, às classes temáticas abalizadas pelas imagens híbridas RGBI e que foram confirmadas em levantamentos de campo compatíveis com a escala 1:50.000.

Tabela 2 - Composições coloridas nos sistemas de cores RGB e RGBI e técnicas de PDI.

\begin{tabular}{|c|c|c|c|}
\hline $\begin{array}{l}\text { Sistemas } \\
\text { de Cores }\end{array}$ & \begin{tabular}{|c|c|} 
Composições \\
Coloridas \\
\end{tabular} & $\begin{array}{c}\text { Razões de } \\
\text { Bandas }\end{array}$ & PC \\
\hline \multirow{3}{*}{ RGB } & $\begin{array}{c}\mathrm{R}(5) / \mathrm{G}(4) / \\
\mathrm{B}(3)\end{array}$ & $\begin{array}{c}\mathrm{R}(6 / 4) / \mathrm{G}(5 / 7) / \\
\mathrm{B}(7)\end{array}$ & $\begin{array}{c}\mathrm{R}(\mathrm{PC} 1) /(\mathrm{PC} 3) \\
\mathrm{B}(\mathrm{PC} 6)\end{array}$ \\
\hline & $\begin{array}{c}\mathrm{R}(6) / \mathrm{G}(5) / \\
\mathrm{B}(2)\end{array}$ & $\begin{array}{l}\mathrm{R}(5) \mathrm{G}(3) \\
\mathrm{B}(\mathrm{NDWI})\end{array}$ & \multirow{2}{*}{$\begin{array}{c}\mathrm{R}(\mathrm{PC} 5) / \mathrm{G}(\mathrm{PC} \\
4) / \mathrm{B}(\mathrm{PC} 6)\end{array}$} \\
\hline & $\begin{array}{c}\mathrm{R}(7) / \mathrm{G}(6) / \\
\mathrm{B}(4)\end{array}$ & $\begin{array}{c}\mathrm{R}(7 / 5) / \mathrm{G}(6 / 4) / \\
\mathrm{B}(5 / 3)\end{array}$ & \\
\hline \multirow{2}{*}{ RGBI } & $\begin{array}{c}\mathrm{R}(5) / \mathrm{G}(4) / \mathrm{B}( \\
3) / \mathrm{I}(8)\end{array}$ & \multirow{2}{*}{$\begin{array}{c}\mathrm{R}(5 / 4) / \mathrm{G}(6) / \\
\mathrm{B}(5 / 3) / \mathrm{I}(8)\end{array}$} & \multirow{2}{*}{$\begin{array}{c}\mathrm{R}(\mathrm{PC} 5) / \mathrm{G}(\mathrm{PC} \\
\text { 6)/B(PC7) } \\
\mathrm{I}(8)\end{array}$} \\
\hline & $\begin{array}{l}\mathrm{R}(6) / \mathrm{G}(5) / \\
\mathrm{B}(2) / \mathrm{I}(8)\end{array}$ & & \\
\hline
\end{tabular}

Legenda: $R G B=$ Sistema de cores primárias Red-Green-Blue; $R G B I=$ Sistema de cores híbrido Red-Green-Blue-Intensity; $N D W I=$ Normalized Difference Water Index $=\left(\right.$ Banda $_{\text {Verde }}-$ 
Banda InfravermelhoPróximo $_{\text {) / (Banda }}$ Verde + Banda Infravermelho Próximo); $P C=$ Principais Componentes .

\subsection{Elaboração dos Mapas de Vulnerabilidade Natural e Ambiental}

As variáveis temáticas do meio físico foram avaliadas conforme a escala de ponderação por Processo Analítico Hierárquico (PAH) proposta por Saaty (2008), que dá suporte à comparação da influência relativa de variáveis pareadas, por meio de uma matriz quadrada, seguindo valores atribuídos por tomadores de decisão em escala contínua de nove pontos de ponderação, que varia entre extremamente a igualmente, para mais ou menos importante contribuição da variável ao objetivo estabelecido (Tabela 3).

Tabela 3 - Escala de valores em nove pontos de importância relativa usados na comparação pareada entre as variáveis. $E X T=$ Extremamente $; M F=$ Muito Fortemente $;=$ Fortemente $;$ $M=$ Moderadamente $;$ IGUAL = Igualmente .

\begin{tabular}{c|c|l|l|l|c|c|c|c}
\hline EXT & MF & F & M & IGUAL & M & F & MF & EXT \\
\hline $1 / 9$ & $1 / 7$ & $1 / 5$ & $1 / 3$ & 1 & 3 & 5 & 7 & 9 \\
\hline \multicolumn{1}{c}{ MENOS } & \multicolumn{5}{c}{ MAIS $\rightarrow$} \\
\hline
\end{tabular}

Na matriz quadrada, cada célula é preenchida com um valor de julgamento conforme essa escala contínua de importância relativa entre os pares (Tabela 4). Como na matriz de comparação pareada há múltiplos meios de avaliação da importância relativa das variáveis, Saaty (2008) sugeriu a determinação de um indicador matemático da consistência das comparações atribuídas aos pares, em função do tamanho da matriz e do máximo autovalor, denominada Taxa de Consistência (TC). A TC indica a probabilidade dos valores da matriz terem sido gerados ao acaso, que Saaty (1991) sugeriu ser aceitável quando consistência das preferências for mantida inferior a 0,1 (ou 10\%) e para a área de estudo foi de 0,09 .

Tabela 4 - Comparação pareada e taxa de consistência aplicada na ponderação de pesos no índice de Vulnerabilidade Natural (VN) para variáveis do meio físico.

\begin{tabular}{c|c|c|c|c|c|c}
\hline Peso & VAR & GEOM & DEC & SOL & VEG & GEO \\
\hline 0,25 & GEOM & 1 & $1 / 3$ & 3 & 3 & 3 \\
\hline 0,42 & DEC & 3 & 1 & 3 & 3 & 5 \\
\hline 0,10 & SOL & $1 / 3$ & $1 / 3$ & 1 & $1 / 3$ & 3 \\
\hline 0,16 & VEG & $1 / 3$ & $1 / 3$ & 3 & 1 & 3 \\
\hline 0,07 & GEO & $1 / 3$ & $1 / 5$ & $1 / 3$ & $1 / 3$ & 1 \\
\hline
\end{tabular}

Taxa Consistência: 0,09 (aceitável)

Os resultantes do PAH foram usados como peso na álgebra de mapas (Tabela 5) e o cálculo compreendeu a combinação linear de cada variável multiplicada pelo peso resultante da PAH para elaboração do mapa de VN (Equação 1). Os pesos obtidos para o VA (Equação 2) foram resultados da inserção do tema uso e cobertura do solo, derivando a baixa influência da antropização na área de estudo.

$$
\begin{aligned}
& \mathrm{VN}=0,25 \times \mathrm{GEOM}+0,07 \times \mathrm{GEO}+0,16 \times \mathrm{VEG} \\
& +0,10 \times \mathrm{SOL}+0,42 \times \mathrm{DEC} \\
& \mathrm{VA}=0,21 \times \mathrm{GEOM}+0,06 \times \mathrm{GEO}+0,17 \times \mathrm{VEG} \\
& +0,09 \times \text { SOL }+0,36 \times \text { DEC }+0,11 \times \text { USO }
\end{aligned}
$$

Onde: $\mathrm{VN}=$ Vulnerabilidade Natural; $\mathrm{VA}=$ Vulnerabilidade Ambiental; GEOM = Geomorfologia; GEO = Geologia; $\mathrm{VEG} \mathrm{=}$ Vegetação; SOL = Solos; DEC $=$ Declividade; USO = Uso e Cobertura do Solo.

Tabela 5 - Resumo dos pesos resultantes do Processo Analítico Hierárquico utilizados na álgebra de mapas para o cálculo da Vulnerabilidade Natural e Vulnerabilidade Ambiental.

\begin{tabular}{c|c|c}
\hline $\begin{array}{c}\text { Variáveis } \\
\text { Temáticas }\end{array}$ & $\begin{array}{c}\text { Vulnerabilidade } \\
\text { Natural }\end{array}$ & $\begin{array}{c}\text { Vulnerabilidade } \\
\text { Ambiental }\end{array}$ \\
\hline Declividade & 0,42 & 0,36 \\
\hline Geomorfologia & 0,25 & 0,21 \\
\hline Vegetação & 0,16 & 0,17 \\
\hline Solos & 0,10 & 0,09 \\
\hline Geologia & 0,07 & 0,06 \\
\hline $\begin{array}{c}\text { Uso e Cobertura } \\
\text { do Solo }\end{array}$ & - & 0,11 \\
\hline TOTAL & 1,0 & 1,0 \\
\hline
\end{tabular}

Os índices de VN e VA, propostos por Grigio et al. (2004), baseiam-se no grau de vulnerabilidade à erosão estipulado a cada classe temática, variando em intervalos de 0,5 entre escores de 1 (estável), 2 (intermediário) e 3 (instável), segundo o conceito de estabilidade das características físicas, onde prevalecem os processos pedogenéticos e aqueles de domínio morfogenético, respectivamente (TRICART, 1977; CREPANI et al., 2001). Nessa perspectiva, com a execução das análises estatísticas em lógica booleana, as classes das variáveis temáticas do meio físico e do uso e cobertura do solo foram convertidas em cinco classes, que variam entre muito baixa e muito alta (BUSMAN, 2016; BUSMAN et al. 2016), conforme os escores (notas) da Tabela 6.

Tabela 6 - Intervalos das classes de vulnerabilidade e escores (notas) por lógica booleana.

\begin{tabular}{c|c|c|c|c}
\hline Muito baixa & Baixa & Média & Alta & Muito alta \\
\hline $1,0-1,4$ & $1,4-1,8$ & $1,8-2,2$ & $2,2-2,6$ & $2,6-3,0$ \\
\hline
\end{tabular}

As notas (escores) empregadas para cada uma das classes temáticas foram sumariadas na Tabela 7.

Igualmente, as variáveis temáticas usadas em $\mathrm{VA}$ e $\mathrm{VN}$ foram comparadas por meio do método por PC, segundo as proporções das classes de vulnerabilidade física da Tabela 7. Através das PC, avaliaram-se as conexões de redundância entre as classes temáticas e identificaram-se aquelas com maiores influências em cada PC, quando com autovalor superior a |0,7|. Segundo Lattin et al. (2011), os valores superiores a $|0,5|$ indicam correlação linear de moderada a forte. 


\subsection{Evolução da Linha de Costa para Determinação do Índice de Vulnerabilidade Costeira}

A avaliação das taxas de erosão e deposição que ocorrem ao longo da LC foi realizada pela determinação do Índice de Vulnerabilidade Costeira (IVC). Neste método sugere-se a parametrização de variáveis físicas e dinâmicas multifontes que influenciam na resistência relativa da $\mathrm{LC}$ aos processos erosivos de longo, conforme proposto por Gornitz et al. (1994) e adaptado por Özyurt e Ergin (2009) e Martins (2015). As variáveis do meio físico consideradas foram: geomorfologia (Figura 2B), declividade (Figura 2C), tipo de infraestrutura ou atividade instalada na LC, taxa de variação e prognósticos da LC. As variáveis dinâmicas foram: amplitude de variação de marés, alturas significativas de ondas, cenários de aumento do NRM. Tais fatores contribuem para os riscos de erosão e, consequentemente, de inundação em trechos específicos de LC, considerando a adequação do IVC às características da área de estudo (ÖZYURT; ERGIN, 2009, 2010; FERNÁNDEZ et al., 2013; BUSMAN, 2016).

Tabela 7 - Notas (escores) das classes temáticas para os índices de vulnerabilidades por lógica booleana.

\begin{tabular}{|c|c|c|c|}
\hline \multicolumn{2}{|c|}{ Declividade } & \multicolumn{2}{|l|}{ Geologia } \\
\hline Classes & Notas & Classes & Notas \\
\hline $0^{\circ}-3^{\circ}$ & 1,0 & $\begin{array}{l}\text { Depósitos eólicos } \\
\text { litorâneos não } \\
\text { vegetados }\end{array}$ & 3,0 \\
\hline $3^{\circ}-8^{\circ}$ & 2,0 & $\begin{array}{l}\text { Depósitos eólicos } \\
\text { litorâneos vegetados }\end{array}$ & 2,5 \\
\hline $8^{\circ}-20^{\circ}$ & 2,5 & Depósitos aluvionares & 2,0 \\
\hline $20^{\circ}-65^{\circ}$ & 3,0 & Formação Barreiras & 1,5 \\
\hline \multicolumn{2}{|c|}{ Geomorfologia } & \multicolumn{2}{|l|}{ Solos } \\
\hline Classes & Notas & Classes & Notas \\
\hline Dunas móveis & 3,0 & \begin{tabular}{|l|} 
Neossolos \\
Quartzarênicos
\end{tabular} & 3,0 \\
\hline Dunas fixas & 2,5 & Neossolos Flúvicos & 2,5 \\
\hline Planície fluvial & 2,0 & $\begin{array}{l}\text { Argissolos Vermelho- } \\
\text { Amarelo }\end{array}$ & 2,0 \\
\hline $\begin{array}{l}\text { Tabuleiro } \\
\text { costeiro } \\
\end{array}$ & 1,0 & Afloramento rochoso & 1,0 \\
\hline \multicolumn{2}{|c|}{ Vegetação } & \multicolumn{2}{|c|}{ Uso e Cobertura do Solo } \\
\hline Classes & Notas & Classes & Notas \\
\hline $\begin{array}{l}\text { Restinga } \\
\text { herbácea }\end{array}$ & 3,0 & Área descobertas & 3,0 \\
\hline $\begin{array}{l}\text { Restinga } \\
\text { arbustiva }\end{array}$ & 2,5 & Área vegetada & 2,5 \\
\hline $\begin{array}{l}\text { Savana } \\
\text { arborizada }\end{array}$ & 2,0 & Área urbanizada & 2,0 \\
\hline $\begin{array}{l}\text { Vegetação } \\
\text { rasteira }\end{array}$ & 2,0 & Afloramento rochoso & 1,0 \\
\hline $\begin{array}{l}\text { Área sem } \\
\text { vegetação }\end{array}$ & 1,0 & Corpo d'água & 0 \\
\hline
\end{tabular}

A Equação 3 foi empregada no cálculo do IVC, baseada na média aritmética simples sem ponderações para, dessa forma, manter-se igualitária a relevância das variáveis físicas e hidrodinâmicas, seguindo a metodologia proposta por Busman (2016). Nesse método, os segmentos da LC são classificados em cinco classes de IVC, variando entre 1 para a menos vulnerável até 5 para a mais vulnerável.

$$
I V C=\frac{\left(\begin{array}{l}
\text { GEOM + VLC + DEC + ALT + AMP } \\
+ \text { CEN + PROGVLC + INFRA + USO }
\end{array}\right)}{9}
$$

Onde: IVC = Índice de Vulnerabilidade Costeira; GEOM = Geomorfologia; VLC = Variação da linha de costa; DEC = Declividade; $\mathrm{ALT}=$ Altura significativa de ondas; $\mathrm{AMP}=$ Amplitude de maré; $\mathrm{CEN}=$ Cenários de aumento do nível relativo do mar (NRM); PROGVLC = Prognóstico da variação da linha de costa; INFRA = Infraestrutura instalada na LC; USO = Tipo de uso ou atividade.

A taxa de aumento no NRM acompanha as propostas de cenários futuros dos Caminhos Representativos de Concentração (RCP, da sigla em inglês para Representative Concentration Pathway) do Painel Intergovernamental sobre Mudanças do Clima (IPCC, sigla em inglês para Intergovernmental Panel on Climate Change), como apresentados pelo Quinto Relatório de Avaliação (IPCC, 2014), entre projeções da mais otimista (RCP 2,6) de taxa média de aumento do NRM de 4,4 mm/ano; taxa média de aumento de $6,1 \mathrm{~mm} /$ ano no cenário intermediário (RCP 4,5); e no cenário mais pessimista (RCP 8,5) com 11,2 mm/ano.

Os dados de amplitude de marés foram obtidos das tábuas de maré do banco de dados da Diretoria de Hidrografia e Navegação (DHN, Marinha do Brasil) para o porto de Natal de 1973 a 2012. Os dados de altura significativa de ondas na LC foram extraídos do Sistema de Modelagem Costeira do Brasil (SMC Brasil) para zona costeira da Barreira do Inferno (MATOS et al., 2020).

As variações da LC, obtidas das imagens multiespectrais e multitemporais, foram analisadas através do cálculo das taxas de erosão e acreção no software Digital Shoreline Analysis System v.4.0 (DSAS) em ambiente SIG (THIELER et al., 2009), baseados em transectos com espaçamentos de $50 \mathrm{~m}$. Nas análises estatísticas foram empregados os módulos Net Shoreline Movement (NSM), que avalia a distância entre a LC mais antiga e uma mais recente num dado período de análise, e para o cálculo das taxas de erosão e acreção utilizou-se a regressão linear dos mínimos quadrados do módulo Linear Regression Rate (LRR).

\section{RESULTADOS E DISCUSSÃO}

Para a análise dos índices de VN e VA, foram categorizadas as classes das variáveis do meio físico, geomorfologia, declividade, vegetação, geologia, solos, uso e cobertura do solo, obtidas nos tratamentos de PDI aplicados sobre as imagens multiespectrais do LANDSAT 5-TM e LANDSAT 8-OLI e confirmadas em levantamentos de campo em escala 1:50.000.

As classes temáticas da declividade, geomorfologia e vegetação são as mais relevantes da definição do comportamento tanto da VN quanto da VA, com somatório significando $83 \%$ e $74 \%$ dos pesos totais nesses índices, respectivamente (Tabela 5). 
Ainda, as classes de solo influenciam em $10 \%$ na VN, enquanto na $\mathrm{VN}$ o tipo de uso e cobertura do solo em $11 \%$, considerando o uso designadamente para atividades militares, com relativamente baixa alteração antropogênica das características naturais da área de estudo. As variáveis físicas inerentes à geomorfologia, declividade, vegetação e solos despontaram como maiores influenciadoras da suscetibilidade à erosão, à inundação e aos movimentos de massa, dada à estreita ligação entre os tipos geológicos e geomorfológicos em zonas costeiras. Por se condicionarem aos aspectos de mudanças em escala do tempo geológico, as classes de geologia recebem nomeadamente, os menores pesos. Com a presença de cobertura vegetacional há menor susceptibilidade do solo à erosão, enquanto na variável uso e cobertura do solo estão refletidas as mudanças rápidas ocorridas no contexto físico de dada região. Tais fatos justificam o emprego dos pesos obtidos no PAH que, mesmo embasados em valores atribuídos por cientistas e gestores públicos, geralmente reduzem as subjetividades e redundâncias nas deliberações sobre a importância das variáveis ao incorporar na ponderação a consistência hierárquica entre elas. Igualmente, e no intuito de reduzir a dimensionalidade das variáveis temáticas, foram realizadas as PC que captaram de 95\% e 99,9\% de variância acumulada nos índices de VA e VN, respectivamente, representando a totalidade das informações originais nas PC1, PC2, PC3 e PC4. A variável recorrente de maior peso foi a vegetação na $\mathrm{PC} 1$ em VA e VN, as variáveis geomorfologia e geologia na PC2 em VA e VN, declividade na PC3 em VN e uso e cobertura em VA, e solos na PC4 em VN.

Os setores com IV nas classes de média, alta e muito alta no mapa de VN, correspondem a $75 \%$ ou $18 \mathrm{~km}^{2}$ da área total (Figura 3A, Tabela 8). O mapa de VN resultante (Figura 4) ressalta a relevância das classes do meio físico no controle da $\mathrm{VN}$ em setores da zona costeira. As áreas de domínio de VN média, alta e muito alta se concentram nas unidades de dunas móveis e fixadas por vegetação arbustiva, que possuem classes com declividades superiores a $20^{\circ}$ e Neossolos Quartzarênicos, conjunto de fatores que caracteriza a área como de alta suscetibilidade aos processos morfogenéticos. No aspecto geológico, há correspondência, obviamente, com os depósitos eólicos litorâneos não vegetados (dunas móveis), depósitos eólicos litorâneos vegetados e praias arenosas. As classes de baixa e muito baixa VN correspondem a $25 \%$ da área de estudo, definindo os setores com predomínio de afloramentos rochosos da Formação Barreiras e depósitos da planície fluvial do Rio
Pium, no contexto do Tabuleiro Costeiro relativamente plano (declividade $<8^{\circ}$ ), com Argissolos Vermelho-Amarelo Distrófico e recoberto por vegetação rasteira ou ausente. Ressalta-se que na análise da VN estão consideradas apenas as variáveis físicas, que interagem com todas as suas propriedades físicas no local. Tal conformação indica que as classes temáticas dominantes na área de estudo são, consistentemente, de alta a muita alta suscetibilidade natural aos processos do meio físico, que promovem alterações locais como, por exemplo, desagregação, transporte e deposição de sedimentos, diante das condicionantes climáticas e hidrodinâmicas locais. Evidências da baixa coesão dos sedimentos e, portanto, baixa estabilidade dos componentes das classes temáticas do meio físico, sobretudo onde a cobertura vegetacional é esparsa ou ausente, estão presentes na formação de sulcos e ravinas em sítios de fluxo de água concentrado sobre os afloramentos rochosos do Tabuleiro Costeiro, na face das falésias marinhas ativas do limite leste, além de escorregamentos de areias nas faces das dunas do limite nordeste, como ocorre no flanco frontal de sotavento do Morro do Careca e é um fatores responsáveis pela redução no volume de sedimentos nessa importante feição de interesse turístico (AMARO et al., 2015).
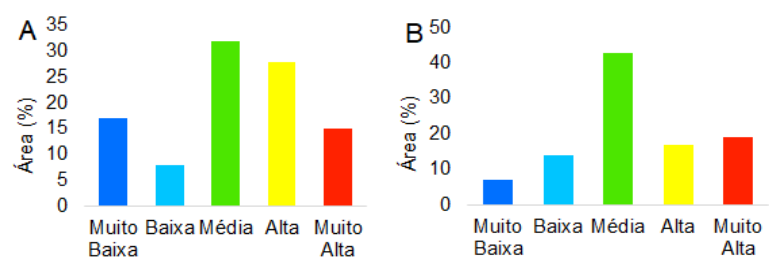

Figura 3 - Distribuição percentual das classes de vulnerabilidade em relação à área total de estudo: (A) Vulnerabilidade Natural; (B) Vulnerabilidade Ambiental.

Tabela 8 - Características dos índices e classes de Vulnerabilidade Natural no contexto da área de estudo.

\begin{tabular}{|c|c|c|c|}
\hline \multicolumn{4}{|c|}{ Mapa de Vulnerabilidade Natural } \\
\hline IV & Classes & Área $\left(\mathrm{km}^{2}\right)$ & Área (\%) \\
\hline $1-1,57$ & Muito Baixa & 4,0 & 16,7 \\
\hline $1,57-1,99$ & Baixa & 2,0 & 8,3 \\
\hline $1,99-2,41$ & Média & 7,7 & 32,1 \\
\hline $2,41-3,00$ & Alta & 6,7 & 27,9 \\
\hline $3,00-3,67$ & Muito Alta & 3,6 & 15,0 \\
\hline \multicolumn{2}{|c|}{ TOTAL } & 24,0 & 100 \\
\hline
\end{tabular}




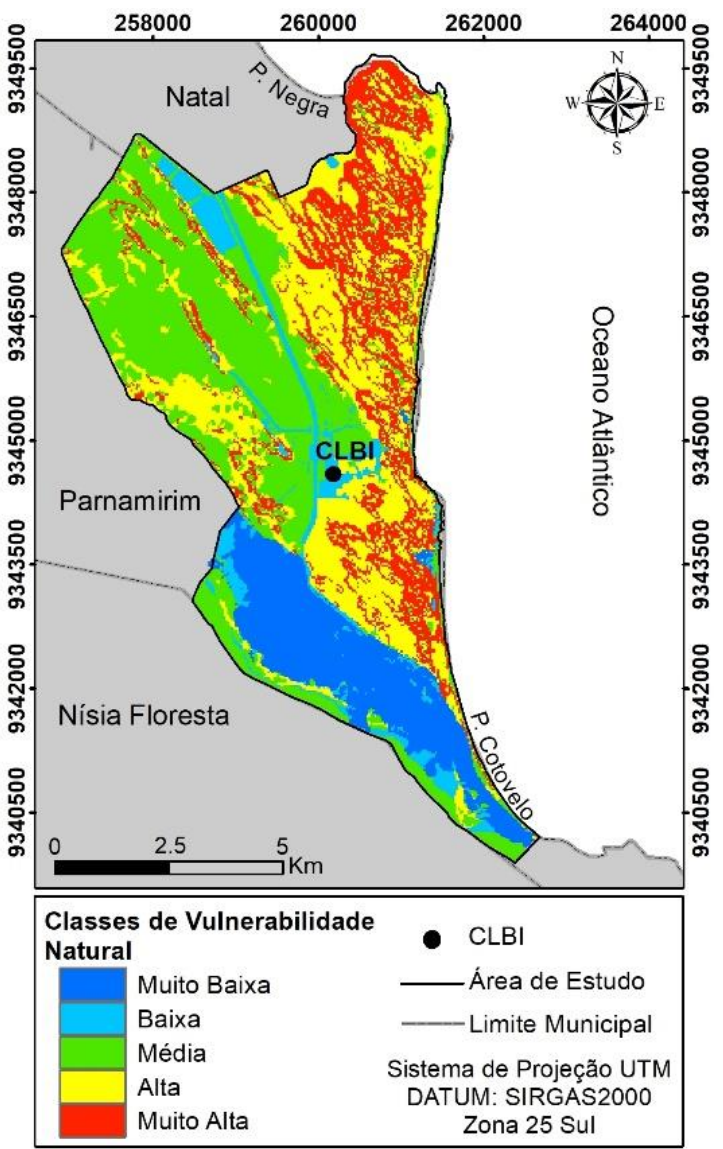

Figura 4 - Mapa de Vulnerabilidade Natural (VN) distribuído em classes para o Centro de Lançamentos da Barreira do Inferno (CLBI).

No mapa de VA, os IV das classes de média, alta e muita alta vulnerabilidade compõem $79,1 \%$ ou $19 \mathrm{~km}^{2}$ da área total do CLBI (Figura 3B, Tabela 9). A Figura 5 mostra o mapa de VA com aumento para $18,7 \%$ da classe de muito alta VA ocorrida no setor do dominado por dunas móveis e fixadas por vegetação arbustiva, com declividades superiores a $20^{\circ}$ e domínio dos Neossolos Quartzarênicos. A classe de média vulnerabilidade aumentou para $43,7 \%$ ou 10,5 km² da área total de estudo (Figura 3B, Tabela 9), abrangendo massivamente o setor de dunas fixadas por cobertura vegetacional e morfologia plana (declividade $<3^{\circ}$ ), onde se instalaram as principais áreas urbanizadas. Fato destacável é que a área de estudo permanece ainda majoritariamente composta por ambientes naturais com baixa influência antrópica.
Destaca-se a ampliação das classes de alta a muito alta VA sobre as porções que delineiam os limites leste e nordeste da área de estudo, onde ocorrem as falésias ativas da Formação Barreiras, praias arenosas e os campos de dunas fixas e móveis, incluindo o setor do Morro do Careca. Outro fato marcante foi a redução das classes de baixa e muito baixa vulnerabilidade para $20,9 \%$ ou 5 $\mathrm{km}^{2}$ do total da área de estudo, restritas aos afloramentos da Formação Barreiras no topo plano do Tabuleiro Costeiro, de Argissolos Vermelho-Amarelo Distróficos com pouca vegetação, e setores urbanizados com alguma infraestrutura instalada, como nas áreas com facilidades da CLBI. A ocupação antrópica do CLBI ocorreu exclusivamente sobre a porção plana do campo de dunas fixas e Tabuleiro Costeiro, a princípio com remoção de vegetação somente nos locais específicos das instalações e em acessos viários, como na $\mathrm{RN}-063$. Contudo, as ocupações antrópicas nas proximidades da linha de costa, junto às falésias ativas e praias arenosas, como na área urbanizada da praia de Cotovelo, ocorrem circundada pelas classes de alta e muito alta VN e VA, marcadamente. Ainda, ressalta-se a complexidade ambiental do posicionamento geográfico do trecho urbanizado da praia de Cotovelo entre a linha de costa e a planície fluvial do Rio Pium. O Rio Pium compõe, acoplado a outros tributários (Pitimbu, Taborda e Água Vermelha), a bacia hidrográfica do Pirangi, imprescindível para a população do Município de Parnamirim, sobretudo no setor costeiro, que faz uso de suas águas para fins agrícolas, de potabilidade e balneabilidade. Tais fatos denotam a inviabilidade da expansão urbana descontrolada nesses setores, sem que os novos projetos urbanísticos provoquem algum dano ambiental e exponham as antigas e novas ocupações ou infraestruturas aos riscos inerentes dos processos costeiros, sobretudo diante da amplificação das forçantes hidrodinâmicas (ondas, marés, correntes e ventos) nos cenários contínuos de mudanças climáticas (AMARO et al., 2015; MATOS et al., 2020).

Tabela 9 - Características dos índices e classes de Vulnerabilidade Ambiental no contexto do Centro de Lançamentos da Barreira do Inferno (CLBI).

\begin{tabular}{|c|c|c|c|}
\hline \multicolumn{4}{|c|}{ Mapa de Vulnerabilidade Ambiental } \\
\hline IV & Classes & Área $\left(\mathrm{km}^{2}\right)$ & Área (\%) \\
\hline $1-1,35$ & Muito Baixa & 1,6 & 6,7 \\
\hline $1,35-2,05$ & Baixa & 3,4 & 14,2 \\
\hline $2,05-2,56$ & Média & 10,5 & 43,7 \\
\hline $2,56-3,00$ & Alta & 4,0 & 16,7 \\
\hline $3,00-3,62$ & Muito Alta & 4,5 & 18,7 \\
\hline \multicolumn{2}{|c|}{ TOTAL } & 24,0 & 100 \\
\hline
\end{tabular}




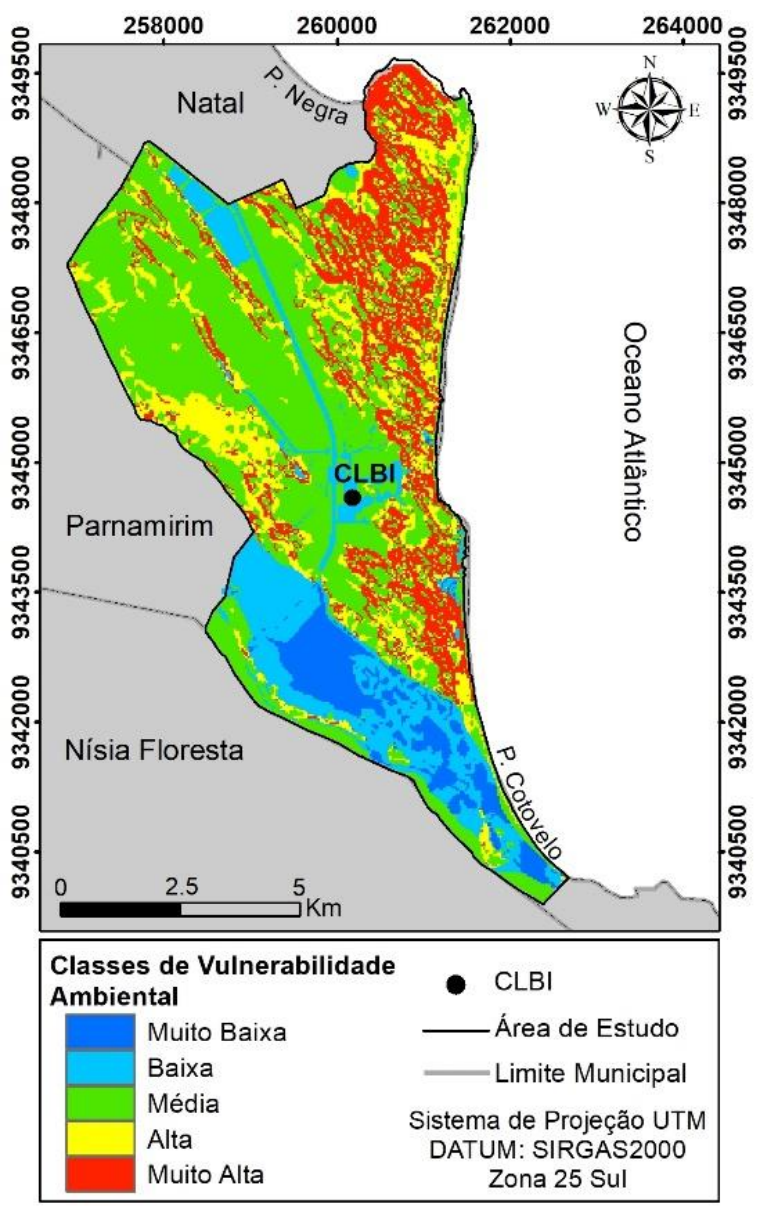

Figura 5 - Mapa de Vulnerabilidade Ambiental (VA) distribuído em classes para Centro de Lançamentos da Barreira do Inferno $(C L B I)$.

Com esse viés condutor foi realizada a análise evolutiva das LC no intervalo de 31 anos com o DSAS em ambiente SIG para o cálculo do IVC, baseado nas imagens da série LANDSAT dos anos de 1984, 1993, 2005 e 2015. Ao longo da LC avaliada houve trechos com deposição de até $40,75 \mathrm{~m}$ e outros em erosão alcançando cerca de $-53,74 \mathrm{~m}$ em largura de faixa de praia entre 1984 e 2015, como mostram as medidas de tendência central dos dados dessa distribuição (Tabela 10). Para a totalidade da LC no contexto do CLBI, a taxa média de erosão foi de $-0,21 \mathrm{~m} / \mathrm{ano}$, correspondendo ao recuo de $-10,23 \mathrm{~m}$ da LC no intervalo temporal analisado, sendo as taxas mais extremas de $-1,69 \mathrm{~m} / \mathrm{ano}$ de erosão e 1,32 m/ano de acreção. Portanto, no cômputo geral, houve mais retração do que acreção nos trechos de LC para período de 1984 a 2015; contudo, esses processos de ganho e perda ainda ocorreram em proporções equilibradas, provavelmente por se tratar de orla marítima com extenso trecho preservado e com baixa ocupação antrópica no CLBI. Tais resultados de variação da LC são condizentes com a tendência da dinâmica sedimentar do litoral oriental do $\mathrm{RN}$, com clima de ondas predominantemente vindas de E e ESE, acompanhando a sazonalidade dos ventos alísios, que promove um transporte longitudinal de sedimentos da ordem de $50.000 \mathrm{~m}^{3} /$ ano no sentido de sul para norte (MATOS et al., 2019). Uma restrição a ser considerada é que, mesmo com as melhores aproximações quanto à similaridade nas condições de marés na data dos imageamentos da série LANDSAT, há diferença de $50 \mathrm{~cm}$ entre o nível da maré da imagem do ano de 1984 em relação as demais imagens, o que pode superestimar os limites da LC e indicar erosão maior no período, por se tratar de um contexto geomorfológico de praia arenosa de baixa declividade.

Tabela 10 - Estatística descritiva da variação da $L C$

\begin{tabular}{l|c|c}
\hline $\begin{array}{c}\text { ESTATÍSTICA } \\
\text { DESCRITIVA }\end{array}$ & $\begin{array}{c}\text { NSM } \\
(\mathbf{m})\end{array}$ & $\begin{array}{c}\text { LRR } \\
(\mathbf{m} / \mathbf{a n o})\end{array}$ \\
\hline Média & $-10,23$ & $-0,21$ \\
\hline Desvio padrão & 18,84 & 0,63 \\
\hline Variância & 354,86 & 0,40 \\
\hline Erosão Máxima & $-53,74$ & $-1,69$ \\
\hline Acreção Máxima & 40,75 & 1,32 \\
\hline
\end{tabular}

A Figura 6 mostra os IVC obtidos para as três projeções de cenários de RCP do IPCC (2014), considerando a média da variação do NRM, em alta confiança até 2100 , sendo: a média de $0,44 \mathrm{~mm}(0,28$ a $0,61 \mathrm{~mm})$ no RCP 2,6 ; a média de $0,53 \mathrm{~mm}(0,36$ a $0,71 \mathrm{~mm})$ no RCP 4,5 ; a média de $0,74 \mathrm{~mm}(0,52$ a $0,98 \mathrm{~mm})$ no RCP 8,5.

Para os cenários RCP 2,6 e RCP 4,5, toda a extensão da LC vulnerabilidade baixa em $100 \%$ do litoral. No cenário RCP 8,5 ocorrem trechos de vulnerabilidade moderada perfazendo cerca de $31 \%$ da LC, marcadamente sobre as falésias marinhas ativas e praias arenosas, setores ainda preservados de atividades antrópicas por estarem locadas entre os limites do CLBI.

O exercício de construção do IVC baseado nas projeções dos RCP teve como balizador o emprego de dados globais de alta confiança, com a perspectiva de avaliação das LC ainda em estado natural, isentas de infraestrutura instalada. Contudo, dados recentes baseados em séries temporais de marégrafos e satélites altímetros sugerem que o aumento médio do NRM no mundo foi de $3,3 \mathrm{~mm} /$ ano entre 1995 e 2015 (HANSEN et al., 2016). Tal fato é condizente com o aumento do NRM na costa equatorial brasileira, baseado em revisões das séries temporais de marégrafos e satélites altímetros (desde 1946), que apontam para valores de aumento entre 2,0 mm/ano e 5,6 mm/ano para o setor entre Salvador/BA e Recife/PE (HARARI; CAMARGO, 1994; MUEHE, 2006; LOSADA et al. 2013; KLEIN; SHORT, 2016). 


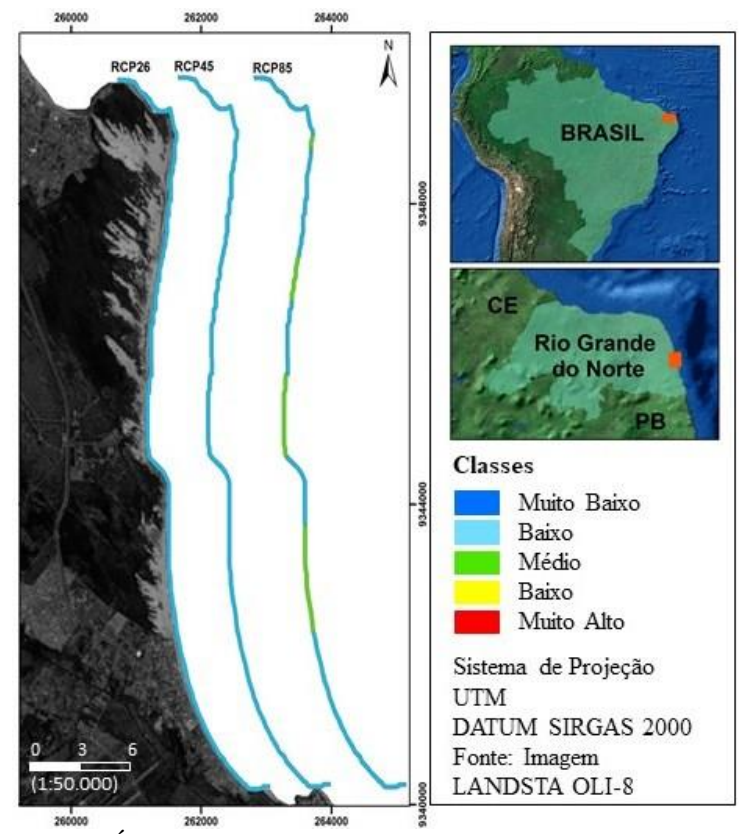

Figura 6 - Índice de Vulnerabilidade Costeira para os cenários de RCP 2,6, RCP 4,5 e RCP 8,5 do IPCC (2014) na linha de costa do Centro de Lançamentos da Barreira do Inferno (CLBI).

\section{CONSIDERAÇÕES FINAIS}

Este artigo avaliou as classes temáticas dominantes do meio físico, declividade, geomorfologia, vegetação, solos geologia, uso e ocupação do solo, e categorizou aquelas mais influentes na elaboração de mapas de VA, VN e IVC para a orla marítima do CLBI na escala 1:50.000. As análises e interpretações das variáveis e classes temáticas e da variação da LC foram baseadas em composições coloridas nos sistemas RGB e RGBI de imagens multiespectrais e multitemporais da série LANDSAT dos anos 1984, 1993, 2005 e 2015, integradas em ambiente SIG e confirmadas em levantamentos de campo.

Por meio dos métodos multicritérios PHA, obteve-se a atenuação da subjetividade de interpretações entre as variáveis temáticas do meio físico, confirmadas na redução da redundância por PC, e combinadas à análise das classes temáticas por operadores booleanos, onde se destacaram a declividade, geomorfologia e vegetação como mais relevantes da determinação do desempenho. As variáveis e classes temáticas foram ponderadas com pesos nos cálculos de VN, VA e IVC.

Os IV das classes de média, alta e muito alta são preponderantes no mapa de VN perfazendo $75 \%$ ou $18 \mathrm{~km}^{2}$ da área total, indicando a importância das unidades de dunas móveis e fixas onde dominam classes de declividades superiores a $20^{\circ} \mathrm{e}$ Neossolos Quartzarênicos. No mapa de VA dominam as classes de média, alta e muita alta vulnerabilidade em $79,1 \%$ ou $19 \mathrm{~km}^{2}$ da área total, com destaque para classe de muito alta VA marcando os setores de dunas móveis e fixas.

A variação da LC entre 1984 e 2015 mostrou valores de erosão de cerca de $-53,74 \mathrm{~m}$ e deposição de até 40,75 m (Tabela 10). A taxa média de erosão na totalidade da LC foi de $-0,21$ $\mathrm{m} / \mathrm{ano}$, correspondendo ao recuo de $-10,23 \mathrm{~m}$ da LC, com taxas extremas de -1,69 m/ano de erosão e 1,32 m/ano de acreção no período. Diante disso, e considerando a sinergia entre as variáveis do meio físico e os extremos de altura significativa de ondas e amplitude de maré, o IVC foi elaborado para os cenários futuros dos RCP 2,6 (otimista), RCP 4,5 (moderado) e RCP 8,5 (pessimista). A totalidade da LC mostrou-se de vulnerabilidade baixa nos cenários RCP 2,6 e RCP 4,5. Já na projeção RCP 8,5, $31 \%$ da LC apresentou vulnerabilidade moderada, destacando os trechos de falésias marinhas ativas e praias arenosas no âmbito do CLBI, sem ocupação antrópica.

Entretanto, os dados para a costa atlântica equatorial nordestina indicam aumento na frequência nos eventos climáticos extremos, na energia das forçantes hidrodinâmicas e, sobretudo, no aumento do NRM (entre 2,0 e 5,6 mm/ano), indicando, no presente, as condicionantes climáticas de cenários menos favoráveis e que tendem ao agravamento futuro. Destaca-se a influência do recorte geográfico do CLBI no balanço ecossistêmico local e regional, por se tratar de APP, com falésias ativas e a presença de cobertura vegetacional conservada, fixadora de campos de dunas e sem instalações antrópicas na LC. Igualmente, distingue-se a relevância na manutenção da LC da área de estudo livre de instalações antrópicas, por se tratar de setor responsável pelo balanço sedimentar da praia de Ponta Negra e do Morro do Careca, já em processo rigoroso de depleção sedimentar diante da ocupação desordenada da orla marítima e dos cenários de mudanças climáticas. Alterações antropogênicas na orla marítima da Barreira do Inferno, desconsiderando os aspectos relatados neste artigo, intensificarão o processo erosivo nos setores costeiros adjacentes e, consequentemente, os impactos ambientais relativos à erosão e inundação nas áreas ocupadas.

Desse modo, a estratégia metodológica adotada, baseada em imagens multiespectrais e multitemporais em composições coloridas híbridas mostrou-se adequada à elaboração de mapas temáticos do meio físico, do uso e cobertura do solo, VN e VA em escala 1:50.000, pertinente ao emprego por gestores públicos no planejamento territorial enfatizando a orla marítima. Os algoritmos de tomada de decisão, amparados em SIG, PHA, lógica booleana e PC, mostraram-se ferramentas eficientes no amparo qualitativo e quantitativo à seleção entre alternativas temáticas nas análises dos IV. Os mapas de VA, VN e IVC resultantes destacaram a elevada influência das variáveis do meio físico do ambiente litorâneo atual, sobretudo diante das projeções futuras de amplificação dos eventos climáticos extremos. Portanto, os materiais e métodos empregados mostram-se aplicáveis a outros setores da orla marítima, sobretudo no contexto da costa atlântica equatorial. Destaca-se que os IV também serão estipulados no futuro por mudanças nas decisões e ações da governança quanto ao uso e ocupação da orla marítima, diante das necessidades inevitáveis de adaptação e mitigação aos perigos da erosão costeira. Como perspectivas futuras sugere-se o detalhamento das variáveis e classes temáticas do meio físico e de sua dinâmica ambiental, por meio de outras técnicas de Geotecnologias Aplicadas de alto desempenho, como imagens de satélites de alta resolução ou ortofotomosaicos de sistema de Aeronave Remotamente Pilotada (Remotely Piloted Aircraft) para avaliação das alterações na orla marítima no curto prazo temporal (anual a sazonal) e elaboração de mapas com maior detalhamento. Igualmente, sugere-se a ampliação dos métodos de análise 
espacial (p.ex. lógica Fuzzy, redes neurais, análise de árvore de decisão) na avaliação das mudanças e transições de mudanças entre as classes temáticas. Ainda, considerando-se a aplicabilidade dos resultados obtidos sobre os IV, sugere-se a elaboração de mapas de risco à erosão como suporte à gestão territorial da orla marítima.

\section{REFERÊNCIAS}

ALMEIDA, L. R.; AMARO, V.E.; MARCELINO, A. M. T.; SCUDELARI, A.C. Avaliação do clima de ondas da praia de Ponta Negra (RN, Brasil) através do uso do SMC-Brasil e sua contribuição à gestão costeira. Revista de Gestão Costeira Integrada, v.15, n.2, p.135-151, 2015.

ALVARES, C. A.; STAPE, J. L.; SENTELHAS, P. C.; GONÇALVES, J. L. M.; SPAROVEK, G. Köppen's climate classification map for Brazil. Meteorologische Zeitschrift, Stuttgart, v. 22, n. 6, p. 711-728, 2013.

AMARO, V. E.; GOMES, L. R. S. ; LIMA, F. G. F.; SCUDELARI, A. C.; NEVES, C. F.; BUSMAN, D. V.; SANTOS, A. L. S. Multitemporal Analysis of Coastal Erosion Based on Multisource Satellite Images, Ponta Negra Beach, Natal City, Northeastern Brazil. Marine Geodesy, Oxfordshire, v. 38, p. 1-25, 2015.

ARAÚJO, V.; REYES, Y.; LIMA, R.O.L.; PELOSI, A.P.M.R.; MENESES, L.; CÓRDOBA, V.C.; LIMA-FILHO, F.P. Fácies e Sistema Deposicional da Formação Barreiras na Região da Barreira do Inferno, Litoral Oriental do Rio Grande do Norte. Geologia USP Série Científica, São Paulo, v. 6, n. 2 , p. 43-49, 2006.

BARBOSA, J. A.; NEUMANN, V. H.; LIMA FILHO, M.; SOUZA, E. M.; MORAES, M. A. Estratigrafia da faixa costeira Recife-Natal (Bacia da Paraíba e Plataforma de Natal), NE Brasil. Estudos Geológicos, Recife, v.17, n. 2, p.3-30, 2007.

BARROS, J. D. Sazonalidade do vento na cidade de natal/RN pela distribuição de Weibull. Sociedade e Território, Natal, v. 25, n. 2, p. 78-92, 2013.

BEVACQUA, A.; YU, D.; ZHANG, Y. Coastal vulnerability: Evolving concepts in understanding vulnerable people and places. Environmental Science \& Policy, Amsterdã, v.82:19-29, 2018.

BEZERRA, F. H. R.; AMARO, V. E.; VITA-FINZI, C.; SAAD, A. Pliocene-Quaternary fault control of sedimentation and coastal plain morphology in NE Brazil. Journal South American Earth Sciences, Amsterdã, v. 14, p. 61-75, 2001.

BORUFF, B. J.; EMRICH, C.; CUTTER, S. L. Erosion Hazard Vulnerability of US Coastal Counties. Journal of Coastal Research, Florida, v. 25, n. 5, p.932-942, 2005.

BRAGA, R. C.; PIMENTEL, M. A. S. Índice de Vulnerabilidade Diante da Variação do Nível do Mar na Amazônia: Estudo de Caso no Município de Salinópolis-Pará. Revista Brasileira de Geografia Física, Recife, v. 12, n. 2, p. 534561, 2019.

BUSMAN, D. V. Zoneamento da dinâmica costeira - aplicação de geotecnologias em apoio à gestão costeira integrada na Praia Atalaia-PA e trecho de praias entre os Municípios de Guamaré e Macau-RN, setor sob influência da indústria petrolífera. Tese de doutorado apresentado ao Programa de Pós Graduação em Geodinâmica e Geofísica da Universidade Federal do Rio Grande do Norte, 2016, 185p.

BUSMAN, D. V.; AMARO, V. E.; SOUZA FILHO, P. W. Análise estatística multivariada de métodos de Vulnerabilidade Física em zonas costeiras tropicais. Revista Brasileira de Geomorfologia, Rio de Janeiro, v. 17, n. 3, p. 499-516, 2016.

CARVAlHO, A. A.; MONTENEGRO, A. A.; SILVA, H.P. da; LOPES, I.; MORAIS, J.E.F.de; SILVA, T.G.F.da. Trends of rainfall and temperature in Northeast Brazil. Revista Brasileira de Engenharia Agrícola e Ambiental, Campina Grande, v. 24, n. 1, p.15-23, 2020.

CREPANI, E.; MEDEIROS, J. S.; HERNANDEZ, P.; FLORENZANO, T. G.; DUARTE, V.; BARBOSA, C. C. F. Sensoriamento Remoto e Geoprocessamento Aplicado ao Zoneamento Ecológico-Econômico e ao Ordenamento Territorial. São José dos Campos: SAE/INPE, 2001.

FERNÁNDEZ, V., GÓMEZ, M. E GUIGOU, B. Coastal vulnerability index to global change in Uruguay. In: $11 \mathrm{TH}$ INTERNATIONAL SYMPOSIUM FOR GIS AND COMPUTER CARTOGRAPHY FOR COASTAL ZONES MANAGEMENT, 2013, Victoria, Abstract... Victoria: EUC, 2013.

FRACASSO, P. Sistema de dunas do Parque das Dunas e Barreira do Inferno, Natal (RN): levantamento geológico/geofísico, elaboração do modelo determinístico e avaliação da vulnerabilidade/susceptibilidade frente as pressões antrópicas. Dissertação de mestrado apresentado ao Programa de Pós Graduação em Geodinâmica e Geofísica da Universidade Federal do Rio Grande do Norte, 2005, 184 p.

GAO, B. NDWI - A normalized difference water index for remote sensing of vegetation liquid water from space. Remote Sensing of Environment, Amsterdam, v. 58, n. 3, p. 257-266, 1996.

GERRITY, B.; PHILLIPS, M, R.; CHAMBERS, C. Applying a Coastal Vulnerability Index to San Mateo County: Implications for Shoreline Management. Journal of Coastal Research, Florida, v. 85, p. 1406-1410, 2018.

GORNITZ, V. M.; DANIELS, R. C.; WHITE, T. W.; BIRDWELL, K. R. The development of a coastal risk assessment database: Vulnerability to sea-level rise in the U.S. southeast. Journal of Coastal Research, Florida, v. 12, p. 327-338, 1994. 
GORNITZ, V.M. Vulnerability of the East coast, USA to future sea level rise. Journal of Coastal Research, Florida, v.9, p.201-237, 1991.

GRIGIO, A.M.; SOUTO, M.V.S.; CASTRO, A.F.; AMARO, V.E.; VITAL, H. \& DIODATO, M.A. Use of remote sensing and geographical information system in the determination of the natural and environmental vulnerability of the Municipal District of Guamaré, Rio Grande do Norte, Northeast of Brazil. Journal of Coastal Research, Florida, v. 39, p.14271431, 2004.

HANSEN, J.; SATO, M.; HEARTY, P.; et al. 2016: Ice melt, sea level rise and superstorms: Evidence from paleoclimate data, climate modeling, and modern observations that $2^{\circ} \mathrm{C}$ global warming could be dangerous. Atmospheric Chemistry Physics, Germany, v. 16, p. 3761-3812, 2016.

HARARI, J.; CAMARGO, R. Tides and mean sea level in Recife (PE): $8^{\circ} 3.3^{\prime} \mathrm{S} 34^{\circ} 51.9^{\prime} \mathrm{W}: 1946$ to 1988 . Boletim do Instituto Oceanográfico, 1994.

IPCC. Fifth Assessment Report. Cambridge: Cambridge University Press, 2014.

KLEIN, A.H.F.; SHORT, A.D. Brazilian beach systems. In Short A.D.; Klein A.H.F. ed. Brazilian beach systems. Coastal Research Library. Springer, 2016, p. 1-35.

KOLLURA, R.V. Health risk assessment. Principles and practices. In: Risk Assessment and Management Handbook. Kollura, R.V., Bartell, S.M., Pitblado, R.M., Scott-Stricoff, R. eds. McGraw-Hill, 1996.

KULP, S.A.; STRAUSS, B.H. New elevation data triple estimates of global vulnerability to sea-level rise and coastal flooding. Nature Communications, California, v. 10, p. 4844. 2019.

LATTIN, J.; CARROLL, J. D.; GREEN, P. E. Análise de dados multivariados. Cengage Learning, 455p, 2011.

LOSADA, I.J.; REGUERO B.G.; MÉNDEZ, F.J.; CASTANEDO, S.; ABASCAL, A.J.; MÍNGUEZ R. Longterm changes in sea-level components in Latin America and the Caribbean. Global Planet Change, Amsterdâ, v. 104, p. 34-50, 2013.

MARTINS, K. A. Vulnerabilidade à erosão costeira e mudanças climáticas através de indicadores em Pernambuco. Dissertação de mestrado apresentada ao Programa de Pósgraduação em Oceanografia da Universidade Federal de Pernambuco, 2015. 107p.

MATOS, M.F.A.; AMARO, V.E.; SCUDELARI, A.C.; BEZERRA, A.C.N. Análises estatísticas de alturas significativas de ondas de série temporal de curto prazo na costa do Rio Grande do Norte. Pesquisas em Geociências, Porto Alegre, v. 46, n. 1, p. 1-24, 2019.

MATOS, M.F.A.; GURGEL, D.F.; SCUDELARI, A.C.; AMARO, V.E. Estimativa da taxa anual e sazonal do transporte longitudinal sedimentar na zona costeira do Litoral Oriental do Rio Grande Do Norte. Revista Brasileira de Geomorfologia, Rio de Janeiro, v. 21, n. 1, p.79-99, 2020.

MCGRANAHAN, G.; BALK, D.; ANDERSON, B. The rising tide: assessing the risks of climate change and human settlements in low elevation coastal zones. Environment and Urbanization, Londres, v. 19, n. 1, p. 17-37, 2007.

MCLAUGHLIN， S.; MCKENNA， J.; COOPER， J.A.G. Socioeconomic data in coastal vulnerability indices: Constraints and opportunities. Journal of Coastal Research, Florida, v. 36, p. 487-497, 2002.

MMA. Especificações e normas técnicas para elaboração de cartas de sensibilidade ambiental para derramamentos de óleo. MMA. 108 p. 2004.

MUEHE, D. Erosion in the Brazilian coastal zone: an overview. Journal of Coastal Research, Florida, v. 39, p. 43-48, 2006.

NICHOLLS, R. J.; WONG, P. P.; BURKETT, V. R.; CODIGNOTTO, J. O.; HAY, J.E.; MCLEAN, R.F.; RAGOONADEN, S.; WOODROFFE, C. D. Coastal systems and low-lying areas. In: Climate Change 2007: Impacts, Adaptation and Vulnerability. 1 ed. Cambridge: Cambridge University Press, 315-356, 2007.

ÖZYURT, G.; ERGIN. A. Application of sea level rise vulnerability assessment model to select coastal areas of Turkey. Journal of Coastal Research. Florida, v. 56, p 248$251,2009$.

ÖZYURT, G.; ERGIN. A. Improving coastal vulnerability assessments to sea-level rise: A new indicator-based methodology for decision makers. Journal of Coastal Research, Florida, v. 26, n. 2, p. 265-273, 2010.

PANTUSA, D.; D'ALESSANDRO, F.; RIEFOLO, L.; PRINCIPATO, F.; TOMASICCHIO, G. R. Application of a coastal vulnerability index. A case study along the Apulian Coastline, Italy. Water, v. 10, n. 9, p. 1218, 2018.

PARTHASARATHY, A.; NATESAN, U. Coastal vulnerability assessment: A case study on erosion and coastal change along Tuticorin, Gulf of Mannar. Natural Hazards, Switzerland, v. 75, p. 1713-1729, 2015.

SAATY, T. L. Decision making with the analytic hierarchy process. International Journal of Services Sciences, Switzerland, v. 1. 2008.

TAGLIANI, C.R.A. 2003. Técnica para avaliação da vulnerabilidade ambiental de ambientes costeiros utilizando um sistema geográfico de informação. In: SIMPÓSIO BRASILEIRO DE SENSORIAMENTO REMOTO, 11, p. 1657-1664. 2003.

THIELER, E. R.; HIMMELSTOSS, E. A.; ZICHICHI, J. L.; ERGUL. A. The Digital Shoreline Analysis System (DSAS) 
version 4.0-an ArcGIS extension for calculating shoreline change. U.S. Geological Survey, 2009.

THIELER, E.R., HAMMAR-KLOSE, E.S. National Assessment of Coastal Vulnerability to Future Sea-Level Rise: Preliminary Results for the U.S. Pacific Coast: U.S. Geological Survey, Open-File Report 00-178, 2000.

TRICART, J. Ecodinâmica. 1 ed. Rio de Janeiro: IBGE. 91p. 1977.

VELOSO, H.P.; RANGEL-FILHO, A.L.R.; LIMA, J.C.A. Classificação da vegetação brasileira, adaptada a um sistema universal. Rio de Janeiro: Fundação Instituto Brasileiro de Geografia e Estatística, 123 p. 1991.
ZHU, Z.-T.; CAI, F.; CHEN, S.-L.; GU, D.-Q.; FENG, A.-P.; CAO, C.; QI, H.-S.; LEI, G. Coastal Vulnerability to Erosion Using a Multi-Criteria Index: A Case Study of the Xiamen Coast. Sustainability, Basiléia, 11, 93. 2019.

UNDESA - United Nation Department of Economic and Social Affairs. UN Ocean Conference, Fact Sheet: Factsheet: People and Oceans. 2017.

\section{AGRADECIMENTOS}

Os autores agradecem à Coordenação de Aperfeiçoamento de Pessoal de Nível Superior Brasil (CAPES) e ao Conselho Nacional de Desenvolvimento Científico e Tecnológico (CNPq) pelo apoio financeiro.

Recebido em: 04/08/2020

Aceito para publicação em: 06/08/2021 